
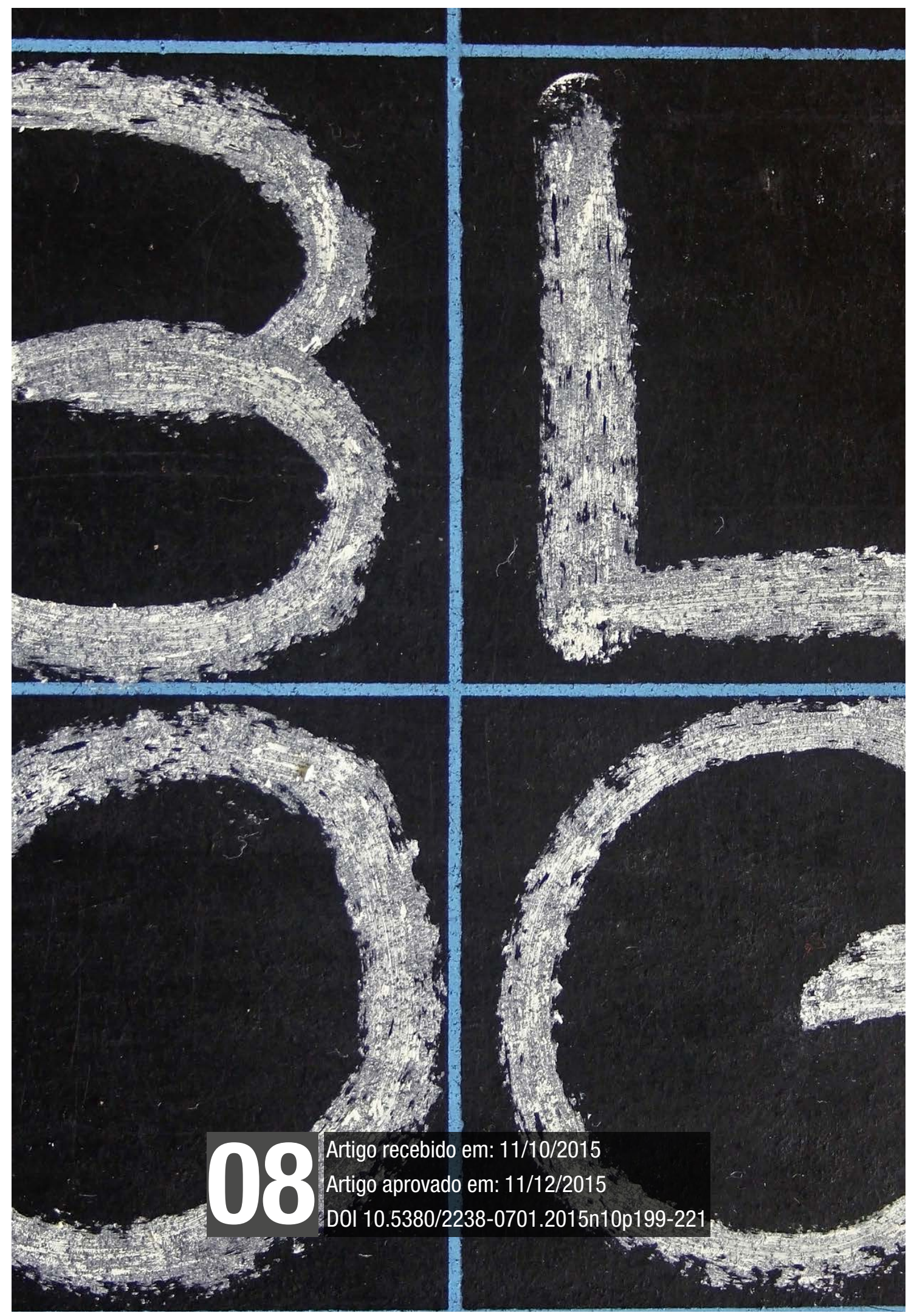
AÇÃO MIDIÁTICA, n. 10. Jul/Dez. 2015. Curitiba. PPGCOM-UFPR. ISSN 2238-0701 


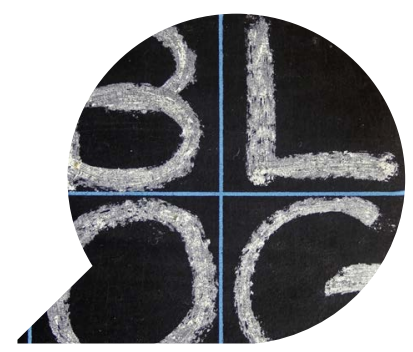

\title{
Narrativas fotojornalísticas: o caso do blog Diário da Foto
}

\author{
Photojournalistic narratives: \\ the case of the blog Diário da Foto
}

\author{
Narrativas fotoperiodísticas: \\ el caso del blog "Diário da Foto"
}

\begin{tabular}{l}
\hline BEATRIZ SALLET $^{*}$ \\
\hline RONALDO HENN $^{* *}$ \\
\hline
\end{tabular}

Resumo: O artigo aborda a produção e edição fotojornalística no blog Diário da Foto, produzido pela editoria de Fotografia do jornal Diário Gaúcho, de Porto Alegre. Nesse espaço, as práticas jornalísticas reconfiguram-se e a fotografia única, característica do fotojornalismo, dá lugar às sequências fotográficas, que relatam histórias através de imagens em séries. A partir da análise do ensaio "Nem os guarda-chuvas aguentam", problematizamos o tratamento do material fotojornalístico no $b \log$ e na versão impressa. Percebemos que o blog converte-se em espaço para o desenvolvimento de outras possibilidades de narrativas que podem acionar camadas pouco exploradas dos acontecimentos. O processo enquadra-se em uma lógica de convergência, na qual as narrativas fotojornalísticas espalhamse e conectam-se mobilizadas por plataformas múltiplas.

\footnotetext{
* Doutora em Ciências da Comunicação pela Unisinos e coordenadora da Faculdade de Fotografia da Unisinos. Contato: bsallet@gmail.com

** Doutor em Comunicação e Semiótica pela PUCSP e professor do PPG em Ciências da Comunicação da Unisinos. Contato: henn.ronaldo@gmail.com
} 
Palavras-chave: Fotojornalismo; Diário da foto; Diário Gaúcho; Segmentação; Público.

Abstract: The article approaches the production and the photojournalistic edition in the blog Diário da Foto, which is produced by the photography editors of the newspaper Diário Gaúcho, from Porto Alegre. In that space, the journalistic practices reconfigure themselves and the single photograph, very characteristic in photojournalism, loses space to the photographic sequences, which tell stories through series of images. From the analysis of the essay "Nem os guarda-chuvas aguentam," we question the treatment of the photojournalistic material on the blog and in its printed version. We noticed that the blog becomes a space for the development of other narrative possibilities that can bring unexplored layers of the events to light. The process falls into a convergence logic, in which the photojournalistic narratives spread and connect themselves mobilized by multiple platforms.

Keywords: Photojournalism; Diário da Foto; Diário Gaúcho; Segmentation; Audience.

Resumen: El artículo aborda la producción y edición de fotoperiodismo en el blog "Diario de Foto" producido por la editora de Fotografía del periódico Diário Gaúcho, de Porto Alegre. En este espacio, las prácticas periodísticas se reconfiguran y la fotografía única, característica del fotoperiodismo, da lugar a las secuencias fotográficas, que cuentan historias por medio de imágenes en serie. Desde el análisis del ensayo "Ni los paraguas aguantan" (Nem os guarda-chuvas aguentam), problematizamos el tratamiento del material de fotoperiodismo en el blog y en su versión impresa. Nos dimos cuenta de que el blog se ha convertido en espacio para el desarrollo de otras posibilidades de narrativas que pueden desencadenar camadas poco exploradas de los eventos. El proceso se emoldura en una lógica de convergencia, en la que las narrativas fotoperiodísticas se extienden y se conectan movilizadas plataformas múltiplas.

Palabras Clave: Fotoperiodismo; Diario da Foto; Diário Gaúcho; Segmentación; Público 


\section{Introdução}

No processo de reconfiguração do jornalismo, que atende hoje à cultura digital, já virou regra as empresas aproveitarem os conteúdos de uma mesma pauta para dar conta da necessidade dos diversos fluxos de conteúdos multiplataformas. As produções provenientes das pautas precisam contar com tratamentos específicos, ou seja, adaptações do mesmo conteúdo, a fim de distribuí-lo pelos diversos canais da chamada convergência digital (JENKINS, 2008; JENKINS, FORD e GREEN, 2013; SILVA JÚNIOR, 2012).

No complexo jogo produtivo das redações dos jornais diários, que funcionam sob a exigência de que se alimentem os diversos canais em multiplataformas (desde o online, as redes sociais, o impresso, os blogs, etc), a produção de conteúdos avoluma-se para os profissionais, que necessitam aprimorar as habilidades multimídias. Por exigência da empresa, jornalistas e fotojornalistas passam a adequar suas coberturas para dar conta de abastecer de informação todos os canais que fazem parte deste fluxo empresarial.

Curiosamente, pelo que observamos nas redações dos jornais diários, não houve uma elevação no volume de pautas, tanto para jornalistas quanto para fotojornalistas. Houve, sim, um alargamento do tempo de trabalho para que cada equipe possa produzir a contento os conteúdos diversos na cobertura do mesmo acontecimento, a fim de facilitar o aproveitamento dos materiais nos diversificados canais. Por exemplo, repórteres e fotojornalistas estão captando vídeos para abastecer o ambiente digital. Ao cobrir um evento factual, os fotojornalistas, em algum momento, param a cobertura para transmitir algum material imagético para o site.

São os novos tempos de jornalismo reconfigurado, como bem abordou Silva Júnior (2012) sobre a demanda por uma necessária polivalência profissional, capaz de lidar com sistemas fotográficos e digitais, principalmente porque "a base tecnológica digital compõe toda a cadeia de produção do fotojornalismo na convergência” (SILVA JÚNIOR, 2012, p. 38) e "a produção em modo de convergência se orienta a uma circulação em multiplataforma” (SILVA JÚNIOR, 2012, p. 41).

São processos que evidenciam uma lógica em constituição do que se chama hoje de jornalismo em redes digitais (HEINRICH, 2011; RUSSELL, 2011), cuja principal característica é a proliferação 
de narrativas mistas, distribuídas em plataformas múltiplas. Especificamente na fotografia, Fred Ritchin (2009) fala em mosaico: ela não é mais um objeto tangível, um retângulo que lembra uma figura, mas uma imagem efêmera feita de tijolos. Isso constitui um processo que ele chama de hiperfotografia, e caracteriza-se justamente nas articulações posteriores ao ato fotográfico em si. Esse conceito lembra a ideia de uma pós-fotografia, postulada por Joan Fontcuberta (2010), que não se restringe apenas à transição da imagem analógica para a digital, mas à toda processualidade implicada nessas dinâmicas, sobretudo as que estão no âmbito da edição (REVILLION, 2015).

$\mathrm{Na}$ atualidade, para ser fotojornalista, não é suficiente saber produzir e operacionalizar tecnologicamente os materiais fotográficos oriundos de uma pauta. É preciso ver além, perceber para que e para quem se está produzindo, e saber as potencialidades que cada material possui, ou o que pode ser aproveitado em cada pauta. Ou seja, o fato de que o repórter fotográfico detém hoje um protagonismo maior nas coberturas in loco, para dar conta das demandas imediatas da cultura digital, acaba por mobilizar os profissionais a progressivamente irem desenvolvendo novas competências, como a de editor, por exemplo.

A necessidade da simultaneidade do online obriga o fotógrafo a identificar qual é a foto factual que melhor comunica o acontecimento, quais delas poderão ser as apostas para o impresso, se a pauta rende, ou pode render um ensaio para o blog, etc. Desta forma, há um maior comprometimento no papel do profissional. Em entrevista realizada com André Feltes ${ }^{1}$, editor do jornal Diário Gaúcho, de Porto Alegre, destacam-se alguns pontos pertinentes a este artigo. Sobre o papel do editor, Feltes foi veemente:

"O fechamento ainda está na mão do editor. Mas aquele processo inicial hoje é feito pelo fotógrafo. [...] me parece que se criou um clima mais democrático, do fotógrafo chegar, descarregar seu material. Já vem editado quando o cara começa a deletar as fotos dele no cartão".

As mudanças nos processos produtivos afetaram tanto os profissionais quanto os públicos segmentados, que, pela construção e consumo

1 A entrevista foi realizada pela autora, na redação do Diário Gaúcho, em 28 de maio de 2014, com fins na pesquisa doutoral, então orientada pelo segundo autor. Na oportunidade, o repórterfotográfico Mateus Bruxel participou da entrevista, em função de que ele é um dos profissionais que mais auxilia na edição dos posts para o blog Diário da Foto. 
de bens simbólicos em diversos formatos, respectivamente, alargam as experiências, ampliam os modos de ver e reeducam a visualidade. Neste sentido, segmentação e conteúdo tornam-se elementos chave.

\section{Diário Gaúcho e o blog Diário da Foto}

O jornal Diário Gaúcho foi lançado no ano de 2000, pelo Grupo RBS - Rede Brasil Sul de Comunicação -, em Porto Alegre/RS, como uma publicação segmentada. Com circulação na região metropolitana e algumas cidades do interior do Estado, o impresso segue a linha do jornalismo popular e tem seu público-alvo estabelecido pela empresa por classes econômicas, atualmente definidas em classes B, C e D (Grupo RBS, 2014).

Seguindo o novo modelo de jornalismo popular, o jornal Diário Gaúcho aposta em conteúdos principalmente das áreas de esportes, polícia, comunidade e entretenimento. O jornal mantém um site, mas os acessos não superam o público do impresso (MERSONI, 2011). Acompanhando a reconfiguração do jornalismo no meio digital, este veículo investe em publicações em sites de redes sociais, como o Facebook, e também criou, em 2010, o blog Diário da Foto, ligado à editoria de Fotografia. Para o blog escoam ensaios, em que sequências fotográficas contam histórias pelas imagens. Antes da criação desta plataforma, as fotografias excedentes ficavam restritas aos arquivos, por falta de espaço.

Com a fotografia digital, normalmente os fotógrafos retornam com muitas fotos de um mesmo acontecimento, e boa parte do material não é utilizado no impresso e no site. O blog, desta forma, torna-se o lugar em que as narrativas fotojornalísticas tomam a forma de ensaios sequenciais. É ele que dá visibilidade às pautas eminentemente fotográficas, elaboradas individualmente pelos fotógrafos do veículo, ou mesmo em posts coletivos, quando narrativas fotográficas são construídas com produções de vários fotógrafos, colegas do grupo RBS.

\section{Da fotografia única à sequência fotográfica}

Historicamente, seja pelas limitações dos equipamentos e materiais fotográficos nos primeiros tempos da fotografia e/ou dos espaços nos jornais impressos, o jornalismo trabalha com o princípio da 
fotografia única, que concentrava as informações da pauta. A foto síntese remete à teoria do instante decisivo, cunhada por Henri Cartier-Bresson (1908-2004): uma imagem em que tudo converge para uma ideia principal.

Apesar de o blog ser uma novidade da cultura digital, a narrativa fotográfica do blog é fruto de modelos predecessores que contam a história pelo método de sequências fotográficas, chamados de picture stories (SOUSA, 2002). Estas sequências não necessariamente seguem a ordem em que o acontecimento ocorreu e foi fotografado ${ }^{2}$, mas a partir das melhores fotos de uma pauta, ou de várias pautas dentro de um mesmo tema. O estilo sequencial, portanto, não é novo, e iniciou na fotografia para usos concomitantemente em campos diversos do conhecimento, desde a ciência, com os primeiros experimentos de Étienne Jules Marey e Eadweard Muybridge ${ }^{3}$, até a arte, como é o caso de Duane Michals, entre outros.

Vasquez (2014) traz uma pesquisa importante sobre a vida e obra do fotógrafo Duane Michals ${ }^{4}$. O autor credita a Michals a revolução que questionou o uso da sequência ordenada da fotografia, colocando em xeque as "[...] bem comportadas reportagens fotográficas, apresentadas de forma linear, com começo, meio e fim claramente definidos" (VASQUEZ, 2014, p. 218). O gênero narrativo pictures stories circulou nas grandes revistas ilustradas da Alemanha, França e Estados Unidos, a partir da década de 1940.

Segundo Vasquez, foi Duane Michals quem primeiro concebeu uma narrativa fotográfica em sequência de forma inteiramente intuitiva. Na sua percepção, ele passou a desenvolver intensa atividade na formatação desse campo específico. Ao empregar, inicialmente, este modelo narrativo, Michals obtinha ferramentas para problematizar e resolver questões que lhe eram incômodas e que solicitavam a superação da imagem única. (VASQUEZ, 2014, p. 219).

Para Vasquez, foi a sólida formação artística de Michals que o conduziu, no início da década de 1960, à criação da sequência fotográfica que, no princípio, apresentavam sequências com estrutura

\footnotetext{
2 A própria natureza da captura fotográfica é sequencial em função do frame-to-frame. Porém as narrativas dos blogs não costumam respeitar esta ordem. Aqui tratamos da constituição de histórias com fotos que pelo seu conteúdo narram e que por isso constroem sentidos.

3 Fotógrafos pesquisadores que desenvolveram métodos de imagens em movimento e seriadas para observar o comportamento dos animais e da natureza.

4 Fotógrafo norte-americano que ficou conhecido por seus retratos de pessoas das ruas, objeto de sua primeira exposição. Mais tarde, Michals revolucionou com suas sequências fotográficas.
} 
muito simples, "mas já abordavam temas caros ao artista, com presença marcante do sobrenatural e do inesperado. O trabalho inaugural, neste setor, foi The woman is frightened by the door (1966)" (VASQUEZ, 2014, p. 222).

Esta breve explanação sobre a origem das pictures stories e sequências fotográficas se faz aqui necessária em função de que se trata de conceitos caros neste debate. A natureza técnica da sequência conta uma história cronológica sobre o acontecimento. Por meio dela, se obtém todas as fotos, inclusive a foto única, ainda utilizada pelo impresso. Imagens sequenciadas, cronologicamente falando, têm funções na pesquisa, por exemplo.

Sousa (2002) define picture stories como um gênero fotojornalístico no qual um conjunto de imagens constitui uma narrativa. Ele pode conter retratos, spot news, entre outros tipos de fotos. Geralmente, as picture stories são constituídas de fotografias diversificadas, com planos gerais, planos médios e planos de detalhes, que mostram o meio, o sujeito e as ações, retratos e uma fotografia que encerra a sequência. Estes tipos são apresentados na ordem em que dão sentido a uma história. Dentro das pictures stories, está o foto-ensaio.

O foto-ensaio é uma história em fotografias que procura analisar a realidade e opinar sobre ela (fotografia com ponto de vista). Uma das diferenças mais significativas e comuns entre as foto-reportagens e os foto-ensaios na actualidade reside na abertura destes últimos a formas alternativas de expressão. (SOUSA, 2002, p. 131).

As narrativas que compõem o blog são fruto da seleção de tudo o que foi produzido e sua sequência não é necessariamente cronológica. Por isso, atende bem ao conceito de ensaio, cujo mote é trazer um fio narrativo sobre um tema fotográfico. Outra característica que se percebe nas narrativas dos blogs fotojornalísticos é o número aleatório de imagens, que pode variar, por exemplo, de cinco a doze fotos, ou tantas quantas estiverem boas para que, ligadas entre si, contem uma história fotográfica. Isto é novo no fotojornalismo e mexe com as convenções, com o que estava institucionalizado. Mateus Bruxel, repórter-fotográfico do Diário Gaúcho, coloca assim sua inserção como editor do blog Diário da Foto:

"O que me interessa dentro dessa possibilidade de ordenar de certa forma as imagens, é a criação do sentido. [...] podem ser dez fotos, 
numa sequência, e contar a história de um jeito; se elas estiverem numa outra sequência, elas podem ser entendidas de outro jeito. Isso me motiva criar quase que uma coisa lúdica”.

Ao tratar da narrativa fotográfica que compõe um post do blog Diário da Foto, durante entrevista à autora, Feltes lembrou um episódio que se toma aqui como proposta empírica.

\section{O caso do ensaio dos guarda-chuvas ${ }^{5}$}

"Um ensaio completamente despretensioso de guarda-chuvas no chão, quebrados", conforme o próprio autor das imagens, o então editor de Fotografia do Diário Gaúcho, André Feltes ${ }^{6}$, gerou uma discussão acirrada entre editores do jornal. As fotografias foram produzidas em 24 de setembro de 2013, nas ruas de Porto Alegre. O clima era de chuva, frio e ventania, e os jornais cobriam os prejuízos causados pelo mau tempo.

Naquele dia, quando se dirigia a pé à redação do Diário Gaúcho, entre o final da manhã e o início da tarde, André Feltes se deparou com uma grande quantidade de guarda-chuvas nas calçadas, quebrados pela intensa ventania. $\mathrm{O}$ editor, que costuma produzir imagens pelas ruas com iphone, começou a registrar as carcaças abandonadas no espaço público. Da rua, André enviou pela internet à redação as fotografias produzidas, que, até aquele momento, eram apenas registros de um fato curioso. Na redação, no lugar de editor do blog, Mateus Bruxel, recebeu as fotografias e decidiu publicar no blog. Mateus relata:

"Foi até meio despretensioso assim, [...] a gente recebeu, foto da chuva e tal, aí olhou, 'tá, mas, vamos botar no blog'. [...] e bah, começou a bombar muito nas redes, deu um pico de audiência que a gente não tinha tido no mês [...] acho que chegou a mais de mil visualizações".

O ensaio fotográfico "Nem os guarda-chuvas aguentam", publicado no blog com texto de Lisiane Lisboa, que trata do clima e da previsão do tempo, por seu modo de produção, é atípico nas rotinas produtivas dos fotojornalistas do jornal Diário Gaúcho, especial-

5 Disponível em <http://wp.clicrbs.com.br/diariodafoto/2013/09/24/nem-os-guarda-chuvasaguentam/?topo $=52,1,1,186, \mathrm{e} 186>$.

6 Feltes desligou-se do jornal Diário Gaúcho cerca de um mês após conceder esta entrevista. 
mente por ser fruto do aproveitamento de um material produzido pelo fotógrafo que estava a caminho da redação e pela utilização de um iphone para captura das imagens, uma vez que os fotógrafos da redação geralmente fotografam com DSLRs ${ }^{7} 35 \mathrm{~mm}$. Além disso, também é preciso considerar a oferta, por parte do próprio editor, de um material inusitado ao jornalismo popular praticado pelo Diário Gaúcho para publicação no jornal impresso.

A cobertura foge às convenções do jornalismo praticado pelo Diário Gaúcho principalmente porque as fotografias capturadas por Feltes são constituídas de um apelo visual, cujo sentido gerado é muito mais estético do que informativo ${ }^{8}$, como normalmente se pratica no jornalismo do Diário Gaúcho, um jornal que notadamente dá muito mais valor às fotografias de personagens do que as subjetivas e de caráter estético.

Uma característica que vincula o blog Diário da Foto com o jornalismo praticado no impresso Diário Gaúcho - e que difere o primeiro de blogs tocados por equipes de repórteres-fotográficos de outros jornais - é o texto na abertura do post. Neste post em questão, pensamos que talvez não fosse o caso de carregar a notícia em texto também. Um título que funcionasse como "gatilho mental" e uma chamada no próprio blog para quem quiser saber mais, remetendo para o impresso e site. Oito fotografias dos guarda-chuvas quebrados foram publicadas no blog Diário da foto, na ordem em que seguem:

7 Digital Single Lens Reflex, em formato $35 \mathrm{~mm}$. Imagens feitas com celulares ou câmeras de menor porte são mais comuns nos casos em que os leitores enviam suas contribuições.

8 Nas coberturas jornalísticas, normalmente os fotógrafos atrelam as fotografias com o texto do repórter. Raras são as vezes que o repórter-fotográfico se pauta e realiza algo mais solto. 


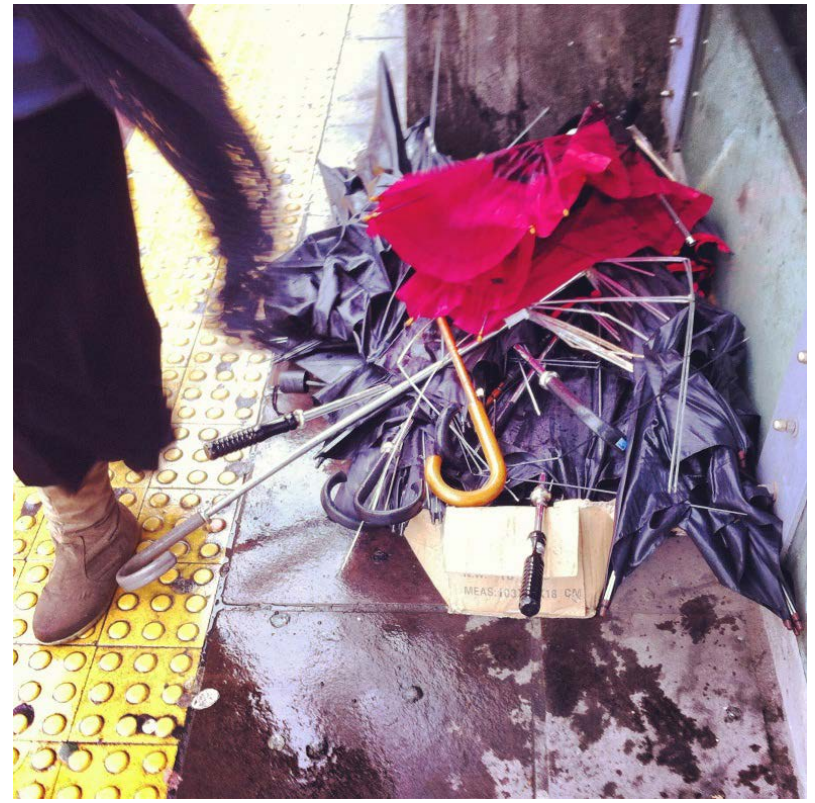

Figura 1: Nem os guarda-chuvas aguentam, André Feltes, 2013

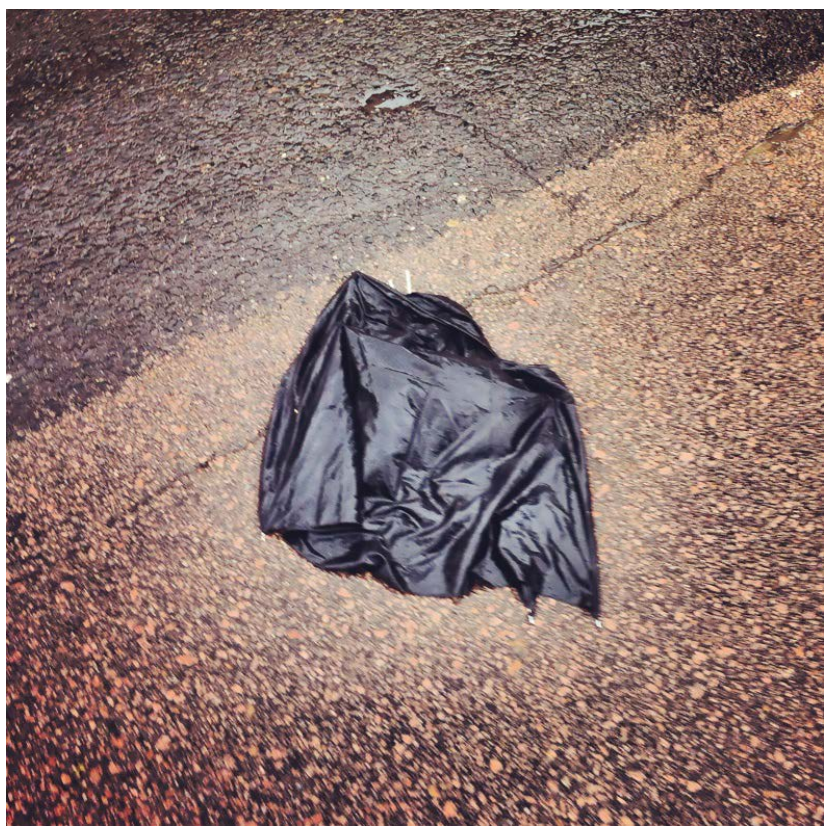

Figura 2: Nem os guarda-chuvas aguentam, André Feltes, 2013 


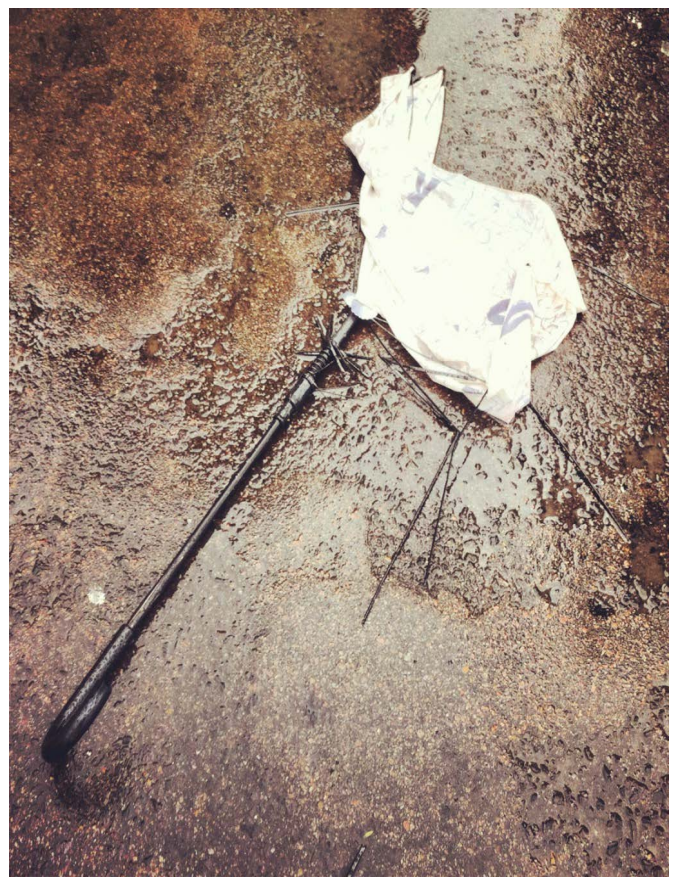

Figura 3: Nem os guarda-chuvas aguentam, André Feltes, 2013

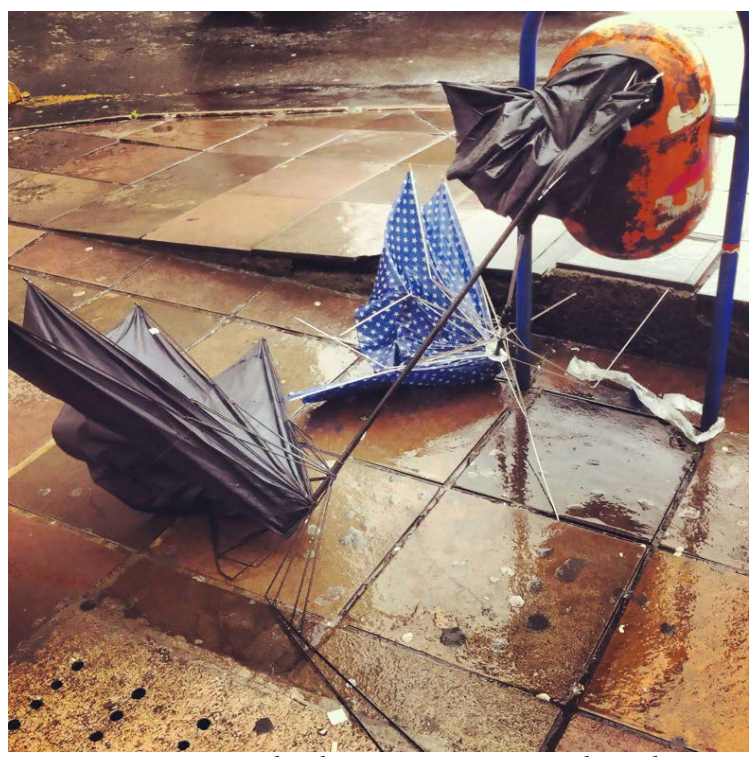

Figura 4: Nem os guarda-chuvas aguentam, André Feltes, 2013 


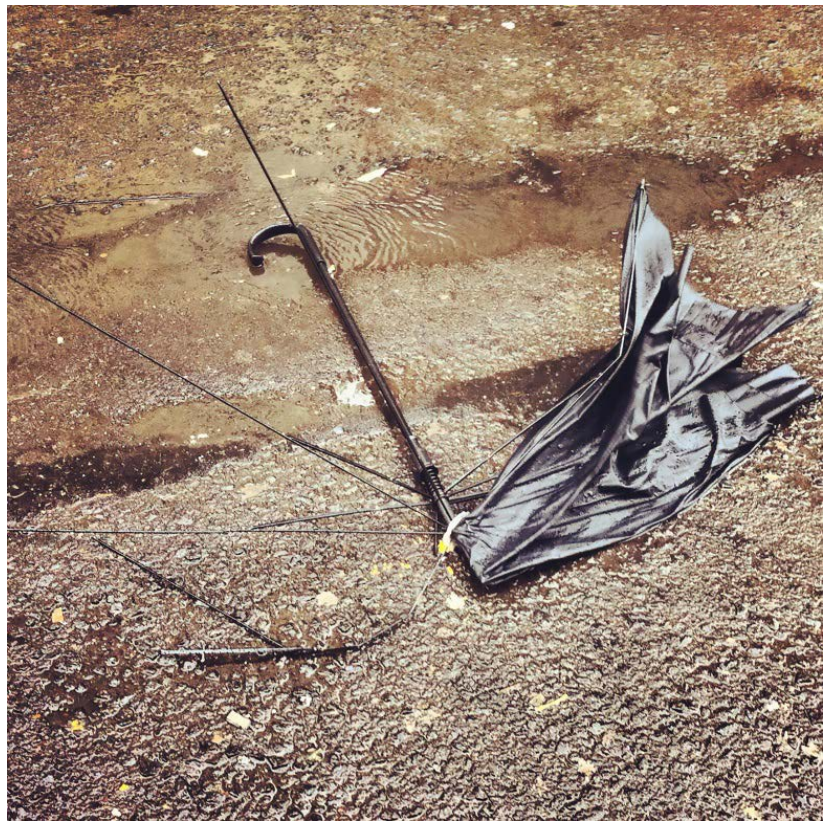

Figura 5: Nem os guarda-chuvas aguentam, André Feltes, 2013

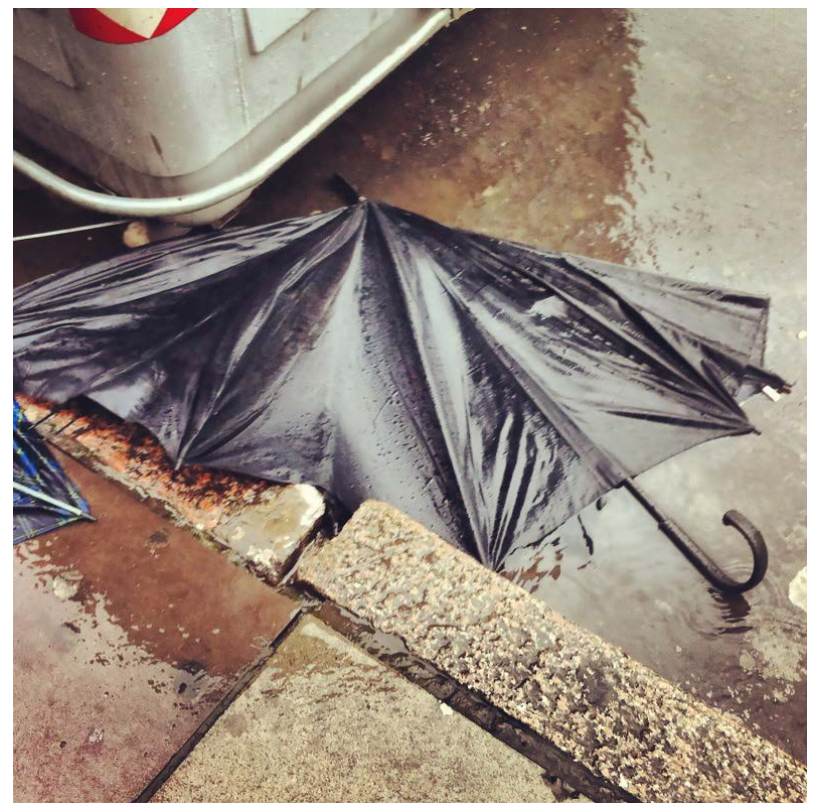

Figura 6: Nem os guarda-chuvas aguentam, André Feltes, 2013 


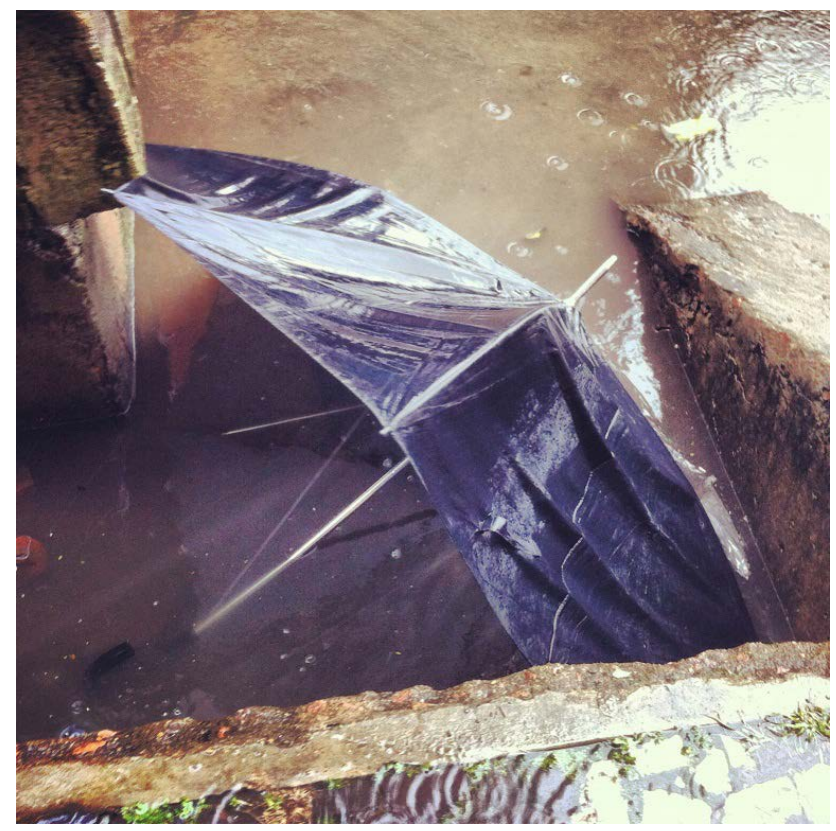

Figura 7: Nem os guarda-chuvas aguentam, André Feltes, 2013

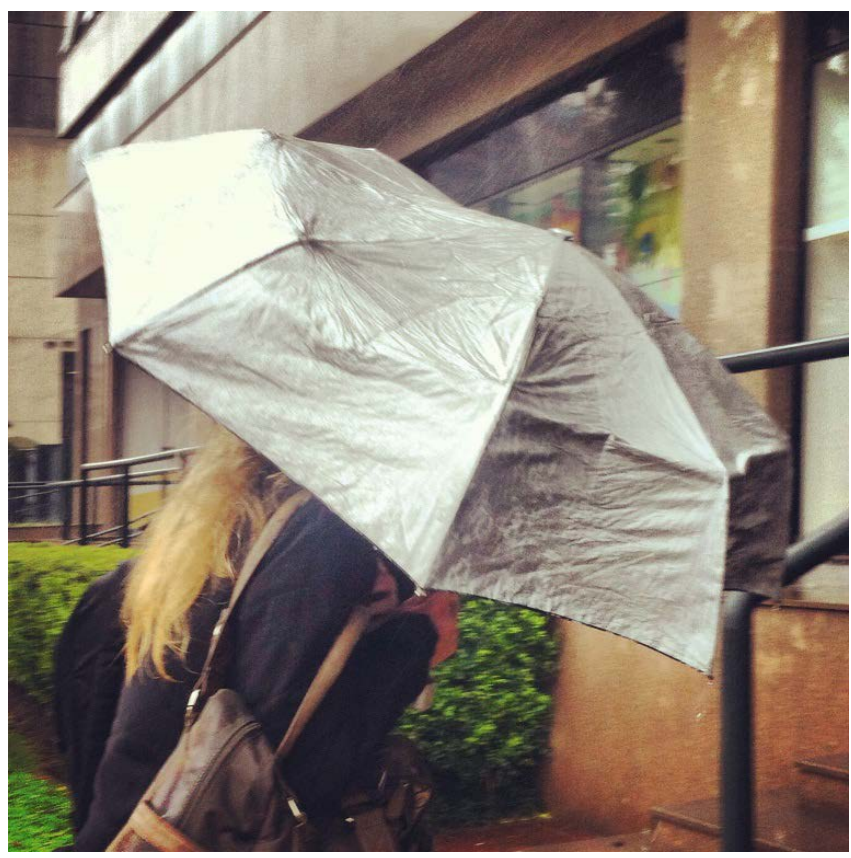

Figura 8: Nem os guarda-chuvas aguentam, André Feltes, 2013 
Trata-se de oito fotos em sequência (Figura 1 a Figura 8), em formato quadrado, cujo assunto "guarda-chuvas quebrados" é o referente fotográfico do ensaio. Centralizados, com enquadramento seletivo para o maior aproveitamento possível do espaço pelo assunto, que prima pelo tema em si - a tempestade que destruiu guarda-chuvas o post mais do que falar de si (dos guarda-chuvas quebrados) dirimiu uma convenção que é primordial no jornalismo popular: o elemento humano, normalmente personagem central na história.

Nas fotografias, o que fica em evidência, além dos ferros retorcidos e tecidos, é o chão de calçadas e ruas molhado, o que se percebe pelo reflexo de luz, poças d'água, meio-fio de calçadas e lixeiras. Em uma delas, onde há uma caixa repleta de guarda-chuvas quebrados, o elemento humano aparece de forma sutil, com a parte do corpo de um sujeito que caminha na calçada. A última imagem do ensaio mostra um guarda-chuva quebrado sendo utilizado por uma pessoa, da qual não se pode ver o rosto. Com algumas exceções, as cores que predominam no ensaio são o preto, o branco e o marrom, o que parece intensificar ainda mais o sentido das imagens: o vento, o frio, a chuva, dias sombrios, sem cores.

Pode-se categorizar as fotos constituintes do ensaio de André Feltes dentro do gênero de notícias, e englobando pelo menos os sub-gêneros: spot news (por se tratar de hard news e acontecimento imprevisível) e pictures stories (que engloba sub-gêneros de foto-ensaios) e feature photos de objetos pictográficos (por se tratar de fotos que encontram grande sentido em si mesmas e não são dependentes de textos explicativos; quando o fotógrafo produz com maior liberdade artística e estilística) (SOUSA, 2002).

De uma perspectiva semiótica, essas distinções evocam as categorias fenomenológicas de Charles Sanders Peirce (2002) quando dimensionadas para pensar a constituição de acontecimentos jornalísticos e suas narrativas (HENN, 2010; HENN e SALLET, 2012). Admite-se que o acontecimento concentra em si a força propulsora das semioses com seus respectivos desdobramentos de sentido: isso implica em infinitas possibilidades de desvendamento do objeto que os signos que os narram encarnam e cujos processamentos dependerão da natureza tanto dos signos, como dos acontecimentos. Isso vale para as configurações verbais e, da mesma forma, para as visuais, sonoras, audiovisuais ou gráficas. 
Normalmente, os acontecimentos são enquadrados na categoria peirciana de secundidade, ou seja, eventos que possuem concretude singular e referentes delimitados: uma hard news. Sua narrativa clássica é a notícia, associada a fotografias que possuem status de flagrante e testemunho. Entretanto, os acontecimentos não estão somente nesse nível de concretude palpável. Eles podem se situar no espaço das impressões qualitativas, estéticas, do que está no campo do sensível $^{9}$. Ao mesmo tempo, os acontecimentos podem estar no campo das ideias, dos conceitos, naquilo que, em linguagem peirciana, chama-se terceiridade. Essas dinâmicas implicam em narrativas de diferentes matizes, incluindo as fotojornalísticas.

As articulações das categorias fenomenológicas não são estanques: o mesmo acontecimento contém as três dimensões, com a predominância de algumas delas. Essa peculiaridade sugere que, conforme o acontecimento é narrado, pode-se salientar alguma camada específica. No caso dos acontecimentos hard news, narrativas que saiam das convenções clássicas da notícia, podem permitir que se aflorem essas camadas mais densamente qualitativas. Os blogs que constroem narrativas diferenciadas, potencialmente podem provocar semioses dessa natureza. É o caso dos guarda-chuvas em tela.

O post gerou um único comentário, curioso, de leitor: "Mostra bem a educação das pessoas. Não são capazes de colocar na lixeira, largam em qualquer lugar. Multa nelas!". Justamente este fato fugiu à preocupação por parte de quem produziu e veiculou as fotos, até porque o fato não estaria nos guarda-chuvas quebrados em seus lugares de destino, as lixeiras, mas nos guarda-chuvas abandonados pela rua, pois seus donos, certamente, correram para abrigar-se da chuva, despreocupados com as lixeiras. Uma única lixeira foi vista, expelindo guarda-chuvas. A notícia não era essa. A notícia constitui-se da própria estética fotográfica proposta por seu autor.

Depois da publicação no blog, as fotografias foram para o portal Clic RBS e para o site da Zero Hora, jornal de referência da Grupo RBS, além do próprio site do Diário Gaúcho. Por tudo isso, cogitouse, conforme André Feltes, por parte dele e dos editores da redação do Diário Gaúcho, publicar o ensaio dos guarda-chuvas na capa do Diário Gaúcho impresso.

9 Segundo Luis Quéré (2005), o acontecimento só pode ser compreendido enquanto tal se afeta alguém, se é vivido no campo da experiência. Nesse sentido, defende-se que acontecimentos não totalmente discerníveis, vivenciado no campo da experiência sensível dos sujeitos, podem entrar na categoria dos acontecimentos jornalísticos e desencadearem narrativas específicas. 
Aqui percebemos mudanças na rotina, que fazem parte da reconfiguração do jornalismo na cultura digital. Primeiro, porque o blog "fura" o impresso. Segundo, porque, ao cogitar a possibilidade de colocar as imagens na capa do jornal, os editores admitem um novo valor-notícia, que se afasta da prática tradicional do jornalismo popular de dar destaque às fontes das matérias, geralmente pessoas que o jornal acredita fazer parte do público-alvo. Essas pessoas, chamadas na redação de "personagens", geralmente estão na capa do impresso, onde dificilmente é observada uma fotografia de motivação apenas estética. (MERSONI, 2014).

Na capa do Diário Gaúcho do dia seguinte, na chamada da matéria que tratava do clima, foi publicada uma fotografia de um personagem relacionado à matéria de uma casa derrubada pelo vento. A escolha justifica-se pela linha editorial, na qual o jornal dá amplo espaço aos problemas sociais. Feltes comenta: "Edição é isso, é escolha".

Posteriormente, o ensaio chamou a atenção da editora do Estadão, Mônica Maia, conforme relata André Feltes:

\begin{abstract}
“[...] logo depois [...] o Estadão, que tinha lá no jornal de domingo uma coluna de pessoas destaques no Instagram, a Mônica Maia, que é a editora, me chamou, e o ensaio que ela mais gostou e escolheu foi o dos guarda-chuvas, que acabou indo para o Estadão. E o Bach (Alexandre Bach, editor-chefe do Diário Gaúcho) me chamou, 'está no Estadão o que a gente não publicou”'.
\end{abstract}

O ensaio que André Feltes protagonizou no blog Diário da Foto seguiu carreira intrigante. Ele não foi aceito para o impresso do Diário Gaúcho, chegou a ser diagramado na contracapa da Zero Hora, mas foi veiculado no portal Clic RBS. Terminou sendo pauta de ZH e publicado, finalmente, no jornal O Estado de São Paulo. Esse ensaio é marcado pelo inusitado, com alguma dose de ineditismo. Ao ser produzido por celular, foi logo absorvido pelo online. Ao ser constituído por uma temática irreverente, foi ponderado em seu valor-notícia no impresso. O que serve para o leitor do jornal impresso Diário Gaúcho e para o leitor do blog Diário da Foto é editorialmente claro, a partir do tratamento nas duas plataformas. 


\section{Segmentação dos públicos e novas possibilidades de narrativas}

Naquilo que se convencionou chamar de jornalismo popular atualmente, os produtores de informação consideram que os leitores precisam identificar-se com os conteúdos publicados. Desta forma, no Diário Gaúcho entram matérias de cunho comunitário, de esportes, de polícia e de entretenimento, principalmente. Nesta linha, ganha destaque as matérias em que pessoas, que não são autoridades nem especialistas, têm espaço para expor suas ideias. Na fotografia, esta característica reflete-se na valorização de retratos desses sujeitos, em detrimento das de cunho estético. Sabemos, também, que a maior parcela do público do jornal popular acompanha o veículo pela versão impressa, por estar migrando gradativamente para as plataformas digitais. Inclusive, a linha jornalística chamada de popular é responsável por alavancar as tiragens dos jornais impressos nos últimos anos, já que os veículos de referência acompanham o crescimento do público no ambiente digital (MERSONI, 2014).

No Diário Gaúcho, a fotografia de maior importância continua sendo o registro do acontecimento, do fato que rompe a rotina de produção. Isso, porque, a maioria dos leitores, que não acessa a internet com frequência, vê no impresso a notícia pela primeira vez. Por outro lado, os jornais de referência começam a se aproximar das práticas de revistas, com reportagens e fotografias não factuais, mas com caráter de interpretação, visando atender um público que já acompanhou a notícia em tempo real e demanda de um aprofundamento no assunto. Com isso, nos jornais tradicionais ganham espaços consideráveis as fotografias onde as características estéticas se sobrepõem ao caráter apenas informativo.

No caso empírico que trazemos, essa realidade fica evidente ao verificarmos que o ensaio seria publicado na contracapa da Zero Hora, caso não entrasse anúncio comercial, e foi aproveitado pelo jornal O Estado de São Paulo. Ao ser publicado no blog do Diário Gaúcho, o veículo assume este como um canal diferenciado do impresso, onde se admite a valorização estética. Desta forma, podemos dizer que o blog é o canal por onde o jornal está buscando ofertar novas visualidades e por onde busca também identificar a resposta do leitor à proposta.

Ao acompanhar os índices de acesso e perceber que houve um aumento considerável, o jornal também começa a perceber que este 
leitor, antes entendido como um sujeito que não teria interesse neste tipo de imagem, pode estar mudando o perfil imaginado. Os internautas, no caso do Diário Gaúcho, são minoria perto dos leitores do jornal impresso, mas precisam ser considerados, uma vez que podem ter migrado do impresso e este caminho possivelmente será seguido por outros leitores, com o acesso cada vez mais facilitado à internet.

À medida que se proporciona outra versão do acontecimento pela fotografia, pode-se também investir em outra perspectiva. Sousa (2002) recupera em Lester (1991) que as categorias que integram as features photos de interesse pictográfico, tanto com elemento humano, quanto de objetos, são as que, aliadas a um layout interessante, podem contribuir para a educação visual dos leitores. Neste caso, o blog, mesmo sendo de um jornal popular, já investe em uma nova oferta aos leitores. E se o jornal impresso tivesse publicado o ensaio, qual seria a reação dos leitores? As vendas em bancas manteriam a média? Por que o jornal não ousa ofertar, gradativamente, esse olhar diferenciado sobre os acontecimentos?

No jornalismo popular, os produtores da informação - por estarem em contato direto com os leitores - ao selecionar os sujeitos e transformá-los em fontes populares, acreditam conhecer seu público e saber o que o interessa. Porém, o que percebemos é um modelo de jornalismo que poderá evoluir mais na educação visual de seus leitores.

\section{Considerações finais}

O ensaio que Feltes propõe é inusitado no que tange às pautas convencionais do Diário Gaúcho, tanto que o jornal impresso preteriu a publicação do mesmo, conforme nos relatou o editor em entrevista, e preferiu publicar no impresso fotos que foram capturadas pela equipe que foi cobrir in loco pessoas que tiveram prejuízos com a chuva e a ventania. Por estas, entre outras razões, pode-se dizer que é um conteúdo constituído para ter abrigo no próprio blog.

O jornal Diário Gaúcho é um jornal que tem seu público como fonte para a produção de suas notícias. Em razão disso, o ensaio não foi aceito pelo impresso, onde os retratos de sujeitos têm grande valorização, mas chegou a ser diagramado para veicular na contracapa do impresso Zero Hora, porém não entrou porque um anúncio de contracapa derrubou o ensaio. 
Desta forma, percebemos que o blog, atualmente, é o meio pelo qual o Diário Gaúcho busca ofertar um novo olhar aos leitores, uma fotografia que transcenda o simples registro dos fatos e os constantes retratos de sujeitos, e o leva ao mundo das subjetividades e da estética. As narrativas, assim construídas, liberam-se um pouco das convenções para revelar camadas semióticas qualitativas dos acontecimentos. Talvez esta seja a estratégia para experimentar as reações do público, oferecendo este novo fotojornalismo a uma parcela menor de leitores, de modo que, posteriormente e gradativamente, também o jornal impresso tenha seu fotojornalismo remodelado. E, com isso, o leitor do Diário Gaúcho também seja inserido no campo da fotografia artística e autoral.

\section{Referências}

CARTIER-BRESSON, Henri. Transcrito de "O Momento Decisivo". Bloch Comunicação, Rio de Janeiro, n. 6, p. 19-25, 2010. Disponível em: <http://ciadefoto.com.br/blog/wp-content/uploads/2010/03/Momento-Decisivo-Bresson.pdf > . Acesso em: 27 jul. 2014.

FONTCUBERTA, Joan. La Cámara de Pandora: La fotografía después de la fotografía. Barcelona: Gustavo Gili, 2010

GRUPO RBS. Diário Gaúcho. Porto Alegre, 2014. Disponível em: $<$ http://www.gruporbs.com.br/atuacao/diario-gaucho/>. Acesso em: 29 jul. 2014.

HEINRICH, Ansgard. Networked Journalism. Londres: Routledge, 2011.

HENN, Ronaldo. O acontecimento em sua dimensão semiótica. In: Marica Benjetti; Virgínia Fonseca. (Org.). Jornalismo e acontecimento, mapeamentos críticos.1ed. Florianópolis: Insular, 2010, v. 1. P. 7793.

HENN, Ronaldo; SALLET, Beatriz. Novas narrativas fotográficas no ciberjornalismo: o acontecimento no campo do sensível. Revista EcoPós, Vol. 15, N. 1, 2012. P. 92-112. 
JENKINS, Henry. Cultura da convergência. São Paulo: Aleph, 2008. JENKINS, H.; FORD, S. e GREEN, J.. Spreadable Media, Creatin, Value and Meaning in a Networked Culture. Nova York: New York University Press, 2013.

LISBOA, Lisiane. Nem os guarda-chuvas aguentam. Diário da Foto, Porto Alegre, 2013. Disponível em: <http://wp.clicrbs.com.br/diariodafoto/2013/09/24/nem=-os-guarda-chuvas-aguentam/?topo52,1,1,,186,e186>. Acesso em: 03 out. 2015.

MERSONI, Carina. Enquadramento jornalístico no retrato: as fontes populares nas fotografias do Diário Gaúcho. 2014. 291 f. Dissertação (Mestrado em Ciências da Comunicação) - Programa de Pós-graduação em Ciências da Comunicação, UNISINOS, São Leopoldo, RS, 2014.

MERSONI, Carina. Fotojornalismo na imprensa tradicional e popular: as linguagens fotográficas dos jornais Zero Hora e Diário Gaúcho. 2011. 142 f. Trabalho de Conclusão de Curso (Bacharel em Jornalismo) -- Curso de Comunicação Social - Habilitação em Jornalismo, UNISINOS, São Leopoldo, RS, 2011.

PEIRCE, C. S.. The Collected Papers of Charles Sanders Peirce. Past Masters, CD-ROM. EUA, InteLex Corporation, 2002.

QUÉRÉ, L. Entre facto e sentido: a dualidade do acontecimento. Trajectos - Revista de Comunicação, Cultura e Educação, Lisboa, n ${ }^{\circ} 6$, 2005. P. 59-76.

RITCHIN, Fred. After Photography. Nova York: W.W. Norton and Co., 2009.

REVILLION, Pedro. A fotografia na palma da mão: fotografia móvel nos processos de edição jornalística. Dissertação (Mestrado em Ciências da Comunicação) - Programa de Pós-graduação em Ciências da Comunicação, UNISINOS, São Leopoldo, RS, 2015.

RUSSELL, Adrienne. Networked, a Contemporary History of News in Transition. Cambridge: Polity Press, 2011. 
SILVA JÚNIOR, José Afonso. Cinco hipóteses sobre o fotojornalismo em cenários de convergência. Discursos Fotográficos, UEL, V.8, $\mathrm{N}^{\circ} 12$, 2012. p. 32-52.

SOUSA, Jorge Pedro. Fotojornalismo: uma introdução à história, às técnicas e à linguagem da fotografia na imprensa. 2002. Disponível em: $<$ http://www.bocc.uff. br/pag/sousa-jorge-pedro-fotojornalismo.pdf $>$. Acesso em: 27 mar. 2015.

VASQUEZ, Pedro Afonso. Sonhos Verdadeiros: a fotografia de Duane Michals. In: BONI, Paulo César (Org). Fotografia: usos, repercussões e reflexões. Londrina: Ministério da Cultura, 2014. p. 210-258. 